\title{
Study on Synchronous Generator Excitation Control Based on FLC
}

\author{
Zhiting Guo, Hong Song, Penggao Wen, Zhizheng Fan \\ Artificial Intelligence of Key Laboratory of Sichuan Province, Sichuan University of Science \& Engineering, \\ Zigong, China \\ Email: gzhiting@163.com
}

Received 8 October 2015; accepted 16 November 2015; published 19 November 2015

Copyright (C) 2015 by authors and Scientific Research Publishing Inc.

This work is licensed under the Creative Commons Attribution International License (CC BY).

http://creativecommons.org/licenses/by/4.0/

c) (i) Open Access

\begin{abstract}
With the development of the national economy, the demand of electric power market has become higher than before. The stable and reliable power system is one of the important national economic securities. Reliability of generator excitation system is one of the important elements to determine the stability of the power system. Traditional PID cannot meet the requirements of the increasingly complex power system due to some defects. This essay introduces FLC control, combining with the traditional PID control. Using Matlab software, we analyze the curve and FLC is better than that by comparing with the traditional PID.
\end{abstract}

\section{Keywords}

Power System Stability, Excitation Control, Traditional PID Control, FLC

\section{Introduction}

Generator's excitation control is a typical non-linear time-variant control system. Due to the complexity of the electric power system, the demands towards the generator's excitation control system have been constantly enhancing. With the development of the control theory, it is a trend of development that the integration of the intelligent control theory and generator's excitation control can achieve a better effect of control. The traditional PID control structure is simple, has a certain robustness, and can achieve better control effect, but because the traditional PID controller needs to manually adjust the parameters, so that the generator excitation adjustment process is more complicated and inconvenient. FLC is the fuzzy logic control, which is characterized by the non dependent control object's mathematical model, and the design method is simple and has strong adaptability, and is easy to implement [1]. In this paper, some defects of the traditional PID excitation control are proposed, and the control of generator excitation system based on FLC is proposed. The fuzzy control is combined with the 
traditional PID control, which makes the excitation system of synchronous generator have better control effect [2]. After the theoretical analysis is completed, matlab simulation software is adopted in simulation, in which a satisfying effect has been achieved. In other words, FLC-based on generator's excitation control system is more effective than the traditional PID excitation control system.

\section{The Principle of Traditional PID Controller}

In the simulation system, the process of the control method is to be measured parameters, such as temperature, pressure, flow, composition, liquid level, current, etc., by the sensor into a unified standard signal into the regulator. In the regulator and the given value, and then compare the difference between the PID after the operation to the executive body, to change the amount of feed, in order to achieve the purpose of automatic adjustment. Simulation PID control system schematic diagram shown in Figure 1.

PID is a linear controller; it constitutes a control program according to a given value $\mathrm{R}$ and the actual value $\mathrm{Y}$ :

$$
e(t)=r(t)-y(t)
$$

And the control rule is:

$$
\begin{gathered}
u(t)=K_{P}\left(e(t)+\frac{1}{T_{1}} \int_{0}^{t} e(t) \mathrm{d} t+T_{D} \frac{\mathrm{d} e(t)}{\mathrm{d} t}\right) \\
G(s)=\frac{U(s)}{E(s)}=K_{p}\left(1+\frac{1}{T_{1} S}+T_{D} S\right)
\end{gathered}
$$

The role of the correction link is:

Proportional links: the proportion of the control system to reflect the deviation of $E(T)$, once produced, the controller immediately to produce control to reduce the deviation.

Integral link: mainly used to eliminate static error, improve the system of no difference. The integral function of the strength is the integral time constant $T, T$ is more, the integration of the more weak, the smaller the $T$, the more integral role.

Differential link: the change trend of the deviation signal, and can be introduced into the system in order to get a valid early correction signal, so as to speed up the system's movement speed and reduce the adjustment time [3].

\section{FLC (Fuzzy Logic Control) Principle}

\subsection{Fuzzy Theory}

Computer cannot be the same as people thinking, reasoning and judgment, only when the given accurate information, the computer can make the wrong judgments, but the human brain even in only part, even not fully to the situation, can be judged, the computer to simulate human thinking and judgment process, it is necessary to have the language of the ambiguous, uncertain information quantitative representation, fuzzy concept [4]. The fuzzy theory has broken the limit of 1 and 0 , and the degree of any one element is 0 or 1 . Fuzzy sets will be clearly focused on 0 and 1 of the boundaries of flat, making it more natural, more close to people's thinking expression. The fuzzy rule is defined on the fuzzy set of rules, often using the "If-then"... Then... In the form of an expert's experience, knowledge, etc. A fuzzy system consisting of a set of fuzzy shares represents an input and output mapping relationship. In this way, the fuzzy system can approximate any connection function.

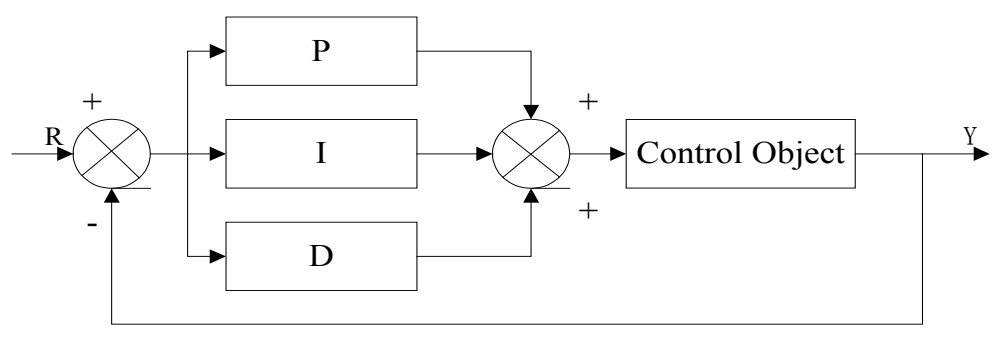

Figure 1. PID control schematic. 


\subsection{Fuzzy Control}

Fuzzy control is a complex system which is difficult to describe. The computer control technology based on natural language and fuzzy reasoning is not dependent on the traditional mathematical model, but is dependent on the fuzzy rules by the operation experience and the expression of knowledge. The basic flow chart of the fuzzy controller is shown in Figure 2.

This framework contains 5 important parts, that is, the definition of variable, fuzzy, knowledge base, logical reasoning and anti-mode.

Defining variables: that is, the state of the program is observed and the action to consider. For example, the input variable is $\mathrm{CE}$ and the output error is $\mathrm{u}$, while the control variable is the next state. Where e, CE, $\mathrm{u}$ are collectively referred to as fuzzy variables.

Fuzzy: the input values are converted to the numerical value of the domain of the input values. The process of measuring the physical quantity is expressed by using the colloquial variables. The relative membership degree is obtained according to the appropriate language value.

Knowledge base: including two parts, including database and rule base, where the database is to provide the relevant definitions of processing fuzzy data, and the rule base is a group of language control rules to describe the purpose and strategy.

Logical reasoning: the fuzzy concept of imitating human judgment, fuzzy logic and fuzzy inference, fuzzy control signal.

Anti-mode: the fuzzy transformation from the inference to the explicit control signal as the input value of the system.

Fuzzy control depends on the "fuzzy rules", which is a scientific and reasonable way to combine the fuzzy control with the excitation control of generator.

\section{Design of Excitation Controller for Synchronous Generator Based on FLC}

\subsection{Synchronous Generator Excitation Model}

Synchronous generator excitation control is mainly composed of excitation control, power module, synchronous generator and measurement module.

The classical synchronous generator voltage regulator excitation model is shown in Figure 3.

In the system, the output winding is synchronous, and the transfer function is a part of the generator when the saturation characteristics of the magnetic circuit of the generator are not considered.

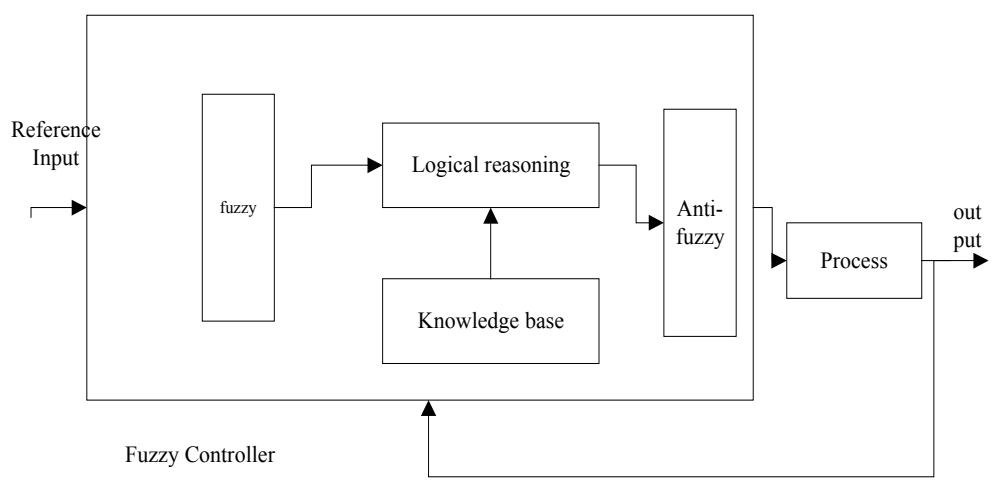

Figure 2. PID control schematic.

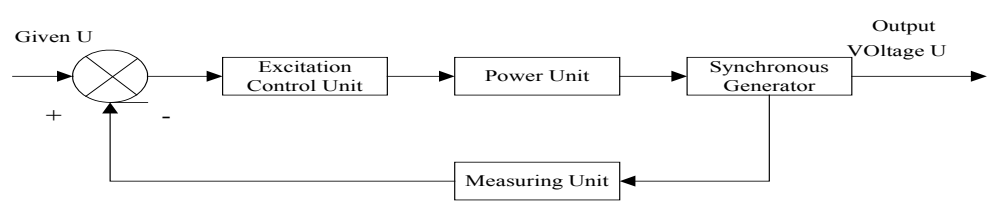

Figure 3. Classic synchronous generator excitation adjustment model. 


$$
G_{G}(s)=\frac{K_{G}}{1+T_{d} s}
$$

$T_{d}$ time constant, $K$ is the amplification factor of the generator. Power unit refers to the output of the excitation controller Upwm, the output voltage of the excitation output voltage $U$, power conversion. The unit can be considered as a first-order inertia link, and the transfer function is shown in the Formula (5):

$$
G_{A}(s)=\frac{U_{f}(s)}{U_{p w m}(s)}=\frac{K_{A}}{1+T_{A} s}
$$

Formula (5), TA for the amplification of the time constant, usually very small, usually take. Voltage measurement unit is the output voltage of the excitation synchronous generator, the input to the digital controller, the change of the input signal, because the rectifier filter circuit has a slight delay, so with a first-order inertia link to describe, expressed as transfer function, such as Formula (6):

$$
G_{M}(s)=\frac{K_{C}}{1+T_{R} s}
$$

In the formula: $K_{C}$ is the ratio of the input and output of the voltage sensor, and the $\mathrm{T}_{\mathrm{R}}$ is the time constant of the filter circuit.

\subsection{Design of Excitation Controller for Synchronous Generator Based on FLC}

\subsubsection{Basic Structure of Excitation Controller for Synchronous Generator Based on FLC}

The basic structure of the excitation controller for synchronous generator based on FLC is shown in Figure 4.

As shown in Figure 4 synchronous generator excitation controller is based on the classical PID controller structure. On the basis of the above, the fuzzy controller is added. The input variables are e and D of the three control parameters of the EC excitation regulator. The output variable is PID, I and P. By the fuzzy control theory and the traditional control theory, the fuzzy rule of expert experience is proposed to control the system's reasoning and judge, and the output to the traditional PID controller, and the fuzzy control of generator excitation is realized [5].

\subsubsection{Formulation of Fuzzy Rules}

In the 2 section, the influence of the traditional PID excitation controller, the three parameter PID on the control factors, and the expert experience, the fuzzy rules are formulated.

When e $<0$, ec $>0$, we should eliminate the deviation, increase the weight of the deviation, close to the steady state, increase the weight of the deviation, and reduce the integral effect.

When $\mathrm{e}<0$, ec $<0$, we should try our best to reduce the overshoot, increase the weight of the deviation.

When e $>0$, ec $<0$, the system basically stable, should reduce the control effect.

When $\mathrm{e}>0$, ec $>0$, the differential parameters, make the system fast and stable [6].

When $\mathrm{e}=0, \mathrm{ec}=0$, the system move into stable state.

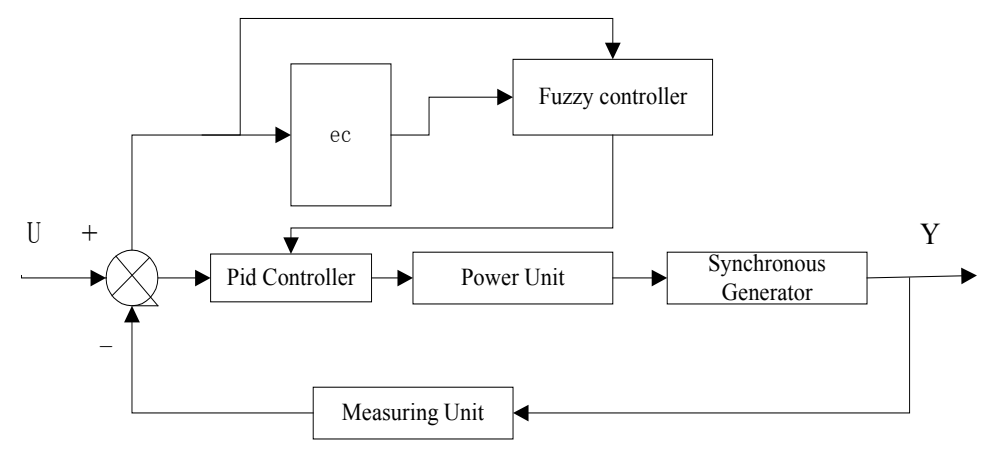

Figure 4. The basic structure of a synchronous generator excitation control based on FLC. 
After the system is stable, the PID parameter is recovered. Based on the above rules, a fuzzy control table is established, and the fuzzy excitation control of generator is realized.

\section{Simulation Analysis}

\subsection{Simulation Module}

In this paper, we use Simulink Matlab to build the model, input fuzzy logic control rules, simulation analysis. The model of the synchronous generator excitation control system based on FLC is shown in Figure 5.

In this paper, traditional PID control chart comparing simulation analysis was shown in Figure 6.

\subsection{Fuzzy Rules Established}

With Using Matlab fuzzy module, made the fuzzy rule input fuzzy logic controller [7]. First create 2 Input 3 Output membership functions, using triangular type, as shown below:

Figure 7 and Figure 8 show the process of building fuzzy rules, namely through two input and three output building fuzzy rules, made the fuzzy rule into the module which analyzed in the previous section, as shown in Figure 9.

Saved as fis files, put into fuzzy control module to achieve the fuzzy control generator excitation control [8].

\subsection{Simulation Results and Analysis}

After the establishment of the model and putting the fuzzy control rules in, the model simulation results are as

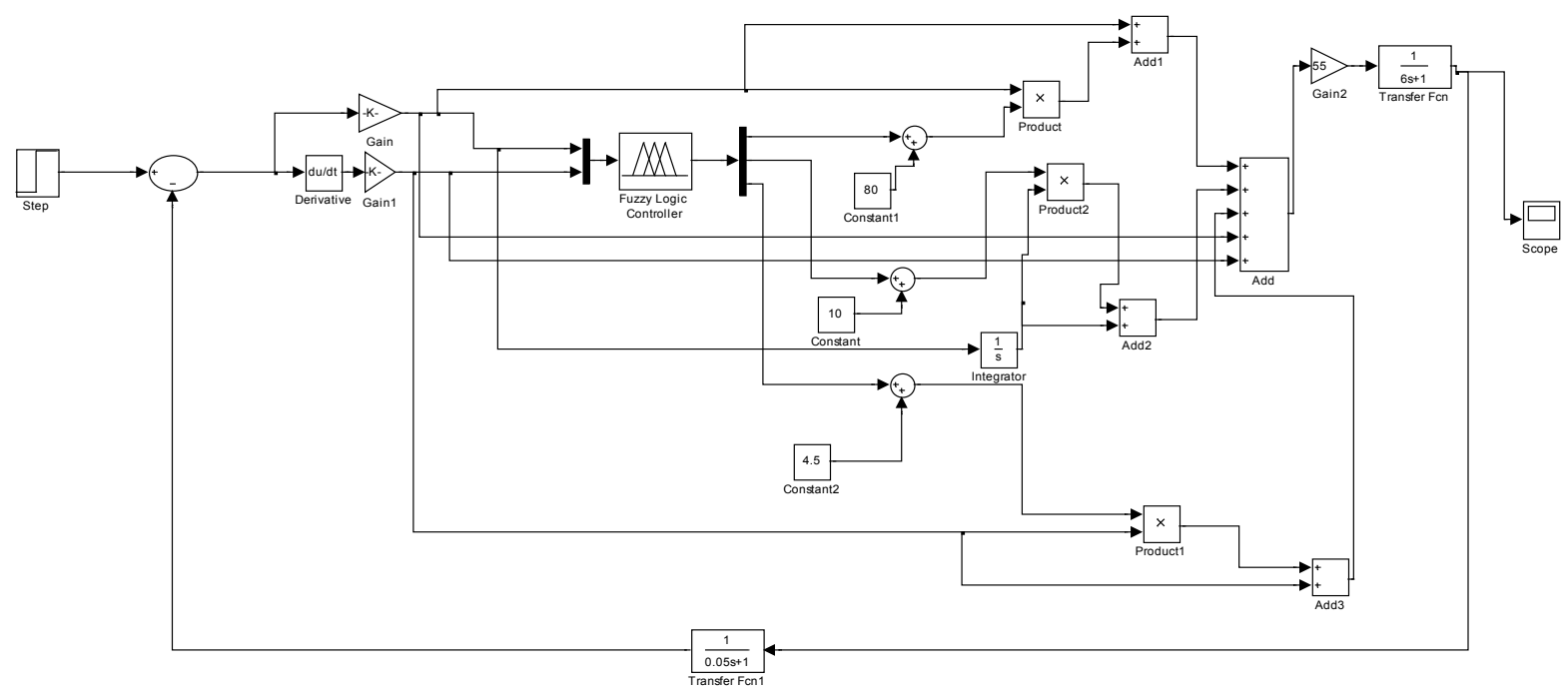

Figure 5. Synchronous generator excitation control system model based on FLC.

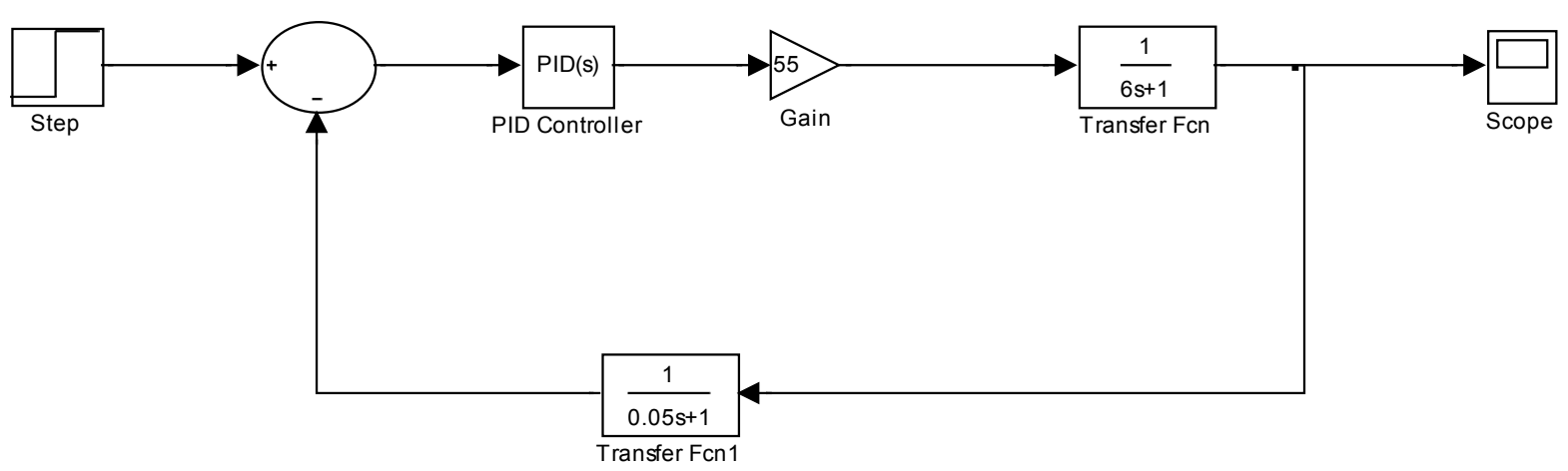

Figure 6. Traditional PID excitation system model. 


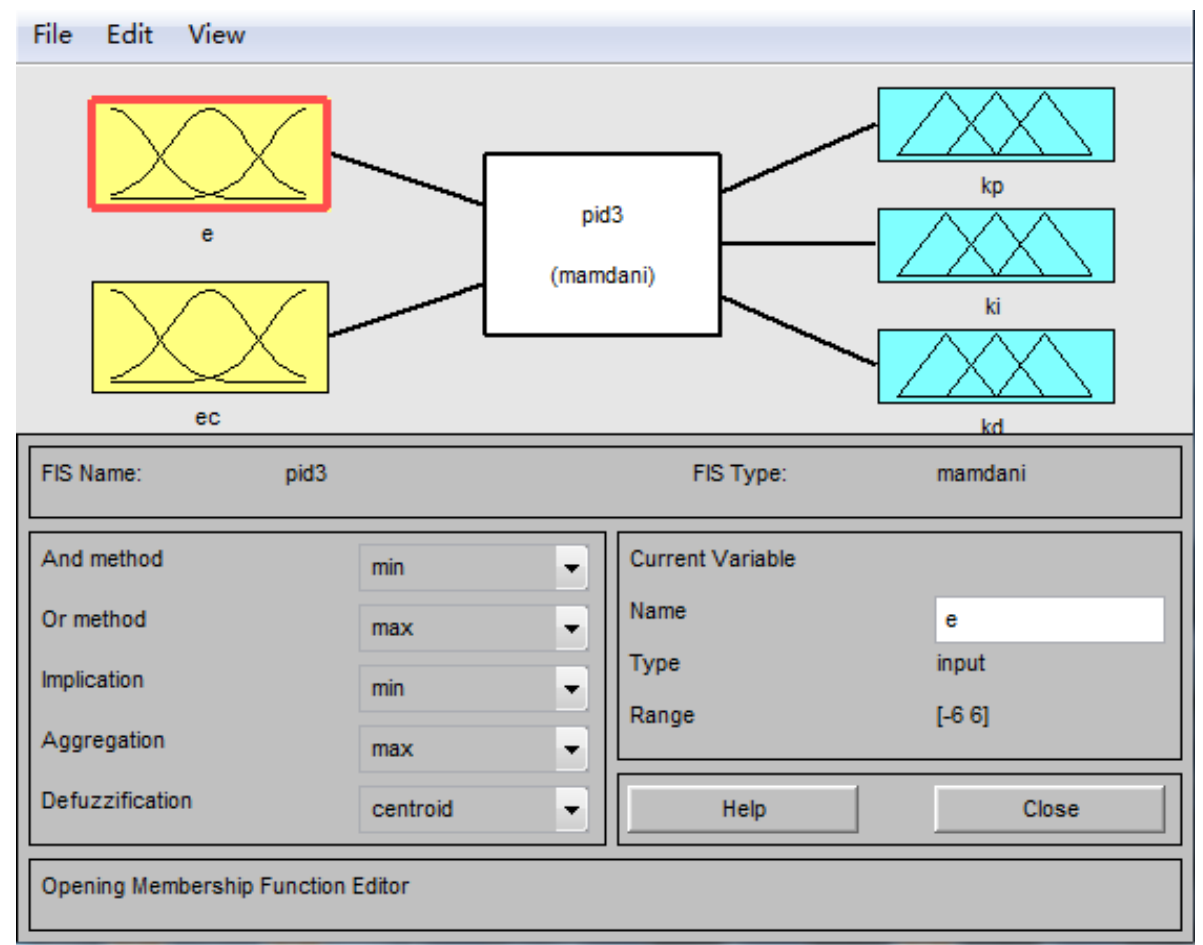

Figure 7. Fuzzy logic rules.

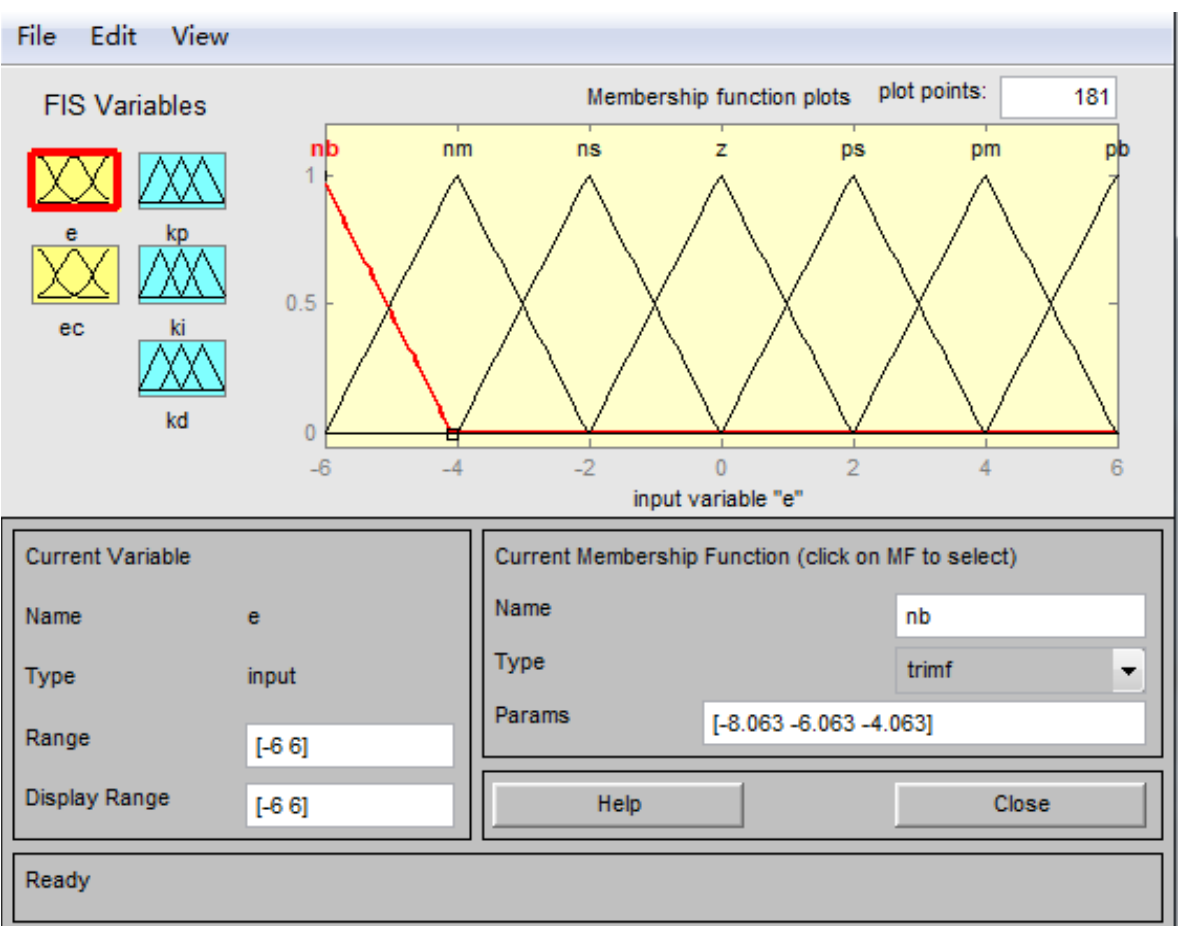

Figure 8. Membership function diagram.

shown below:

Figure 10 and Figure 11 analyze results; synchronous generator excitation control system based on FLC has lower overshoot. During the simulation of control, the synchronous generator excitation control system based on FLC can have an adjustment in real time according to the error and the experience. It has better adaptability. 


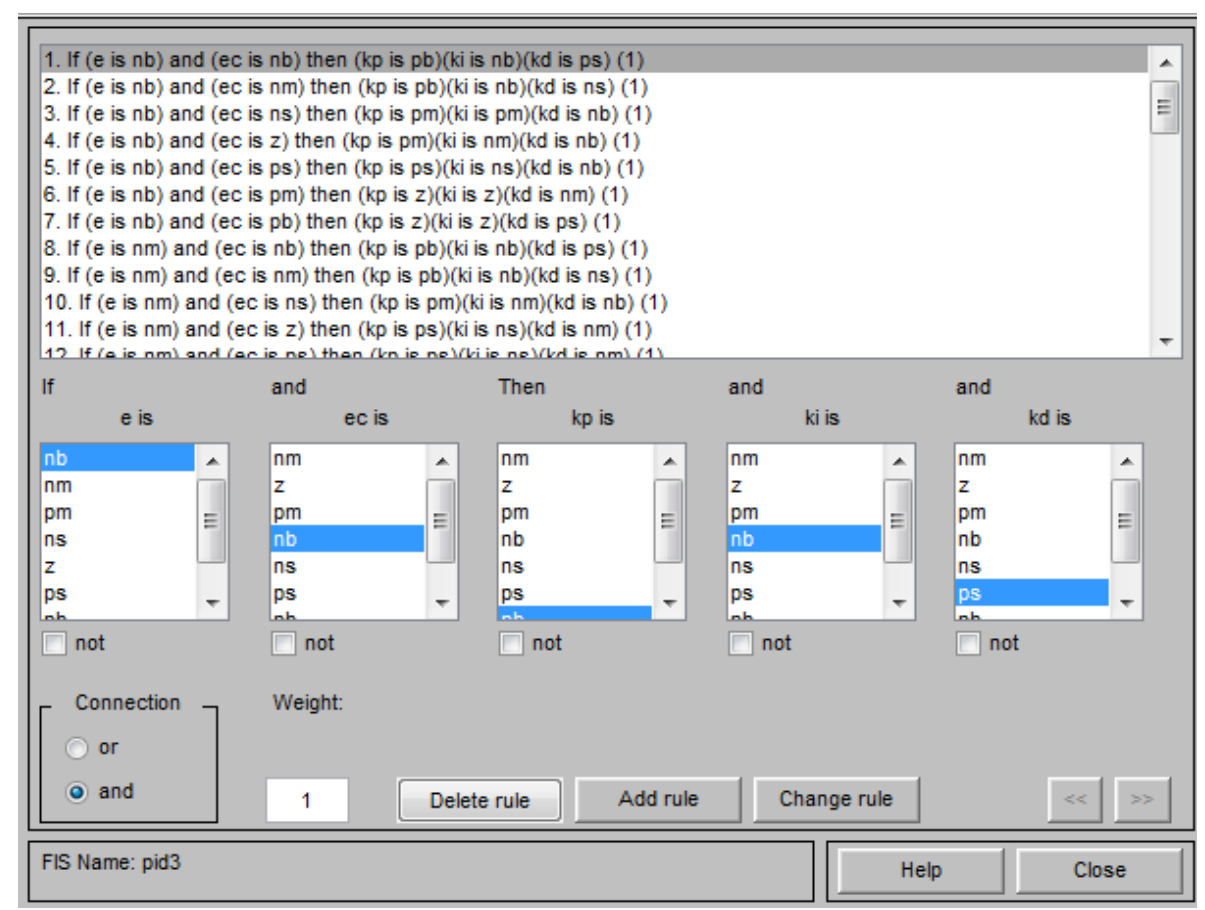

Figure 9. Fuzzy rules established.

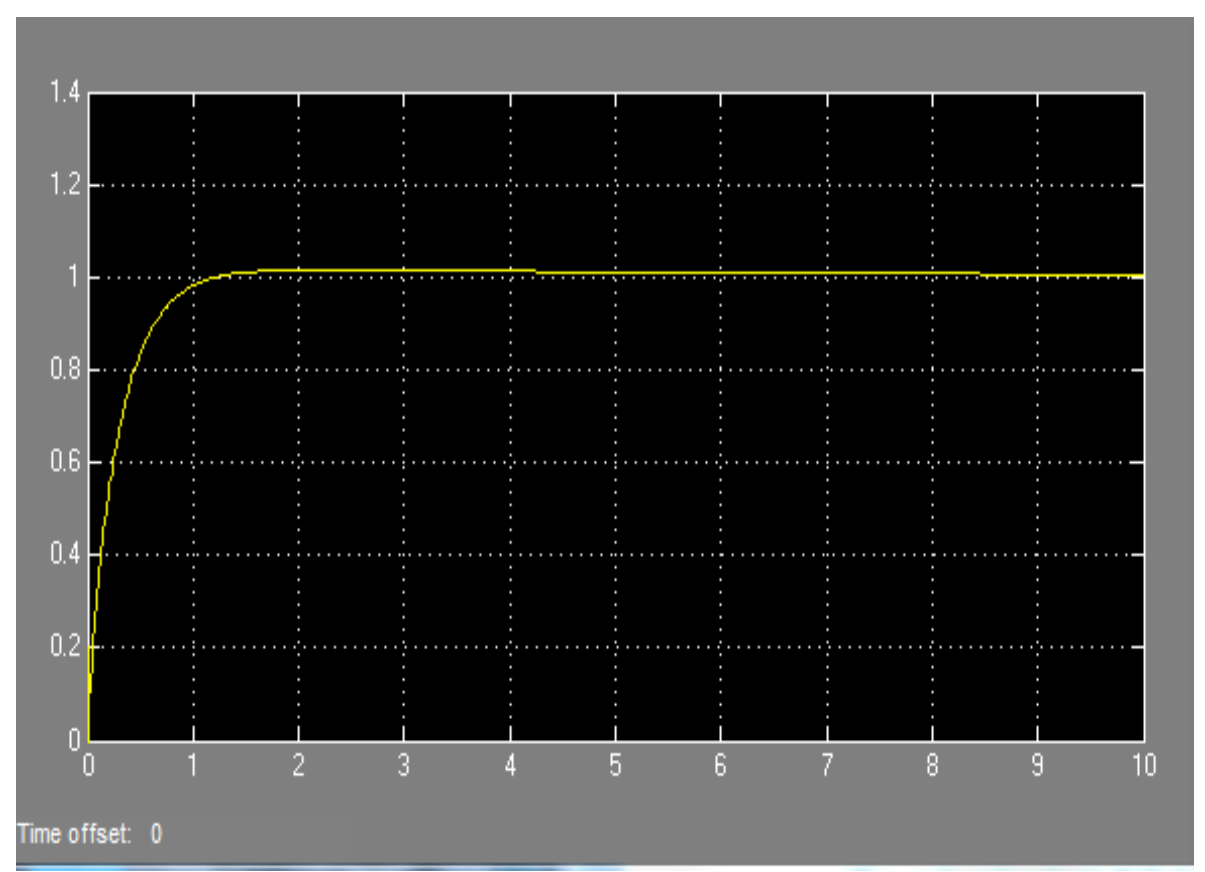

Figure 10. Simulation of synchronous generator excitation control based on FLC.

Control debugging process compared with traditional PID excitation control has better results [9].

This paper analyzes the generator excitation control based on FLC; adding FLC into generator excitation control system is mainly aimed at the feature of generator excitation control system which is nonlinear, time varying, and complex. After adding fuzzy control system, the generator excitation control system can do more reasonable measures according to the experience which make the generator excitation control system more reliable and effective. The controller based on FLC is designed with advantages of fuzzy control with that of PID control com- 


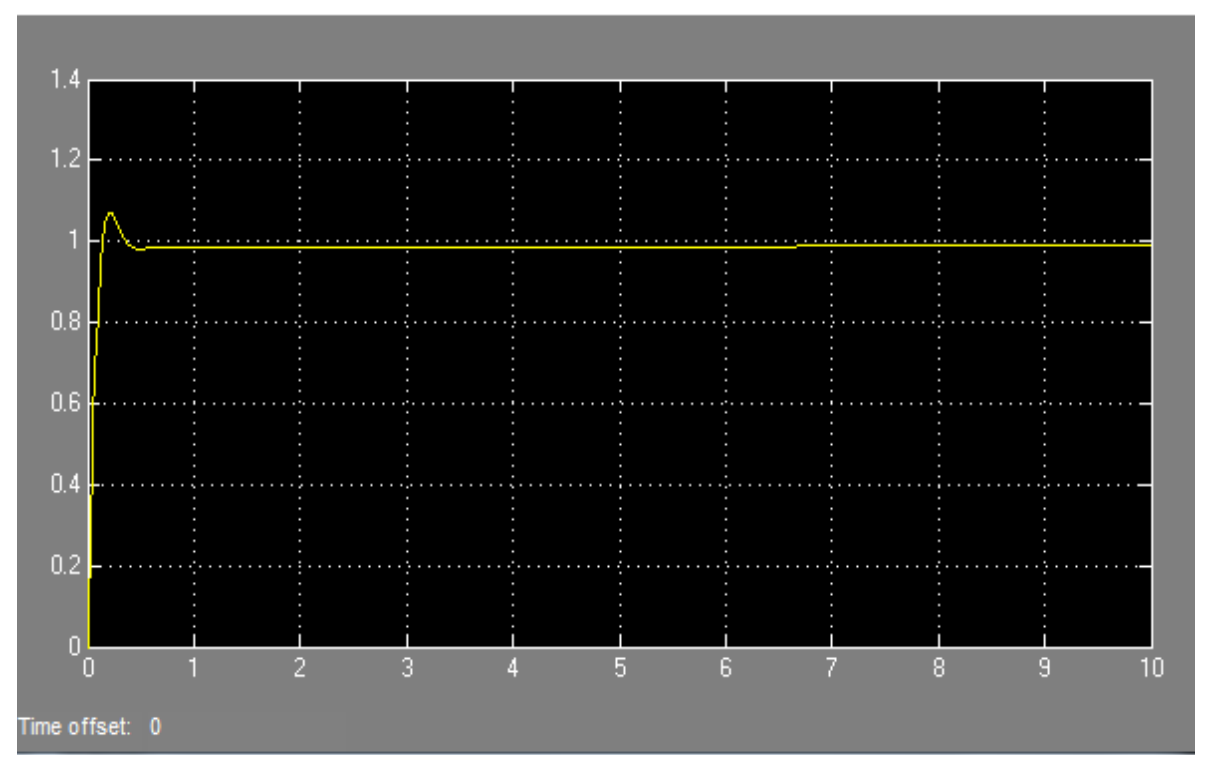

Figure 11. Simulation of traditional pidsynchronous generator excitation control.

bined, which is characterized by simpleness, high accuracy of PID control, good adaptability and speed ability of fuzzy control.

\section{Fund}

Sichuan University of Science \& Engineering Cultivation Project 2012py18, and Artificial Intelligence of Key Laboratory of Sichuan Province Project 2014RYY05, 2015RYY01.

\section{References}

[1] Masmoudi, A., Michalczuk, M., Ufnalski, B., et al. (2015) Fuzzy Logic Based Power Management Strategy Using Topographic Data for an Electric Vehicle with a Battery-Ultracapacitor Energy Storage. Emerald Group Publishing Limited, Bingley.

[2] Yu, Y.Y. (2007) Power System Analysis. China Electric Power Press, Beijing.

[3] Zhao, J.B. (2010) MATLAB Control System Simulation and Design. China Machine Press, Beijing.

[4] Zhao, Z.Y. and Xu, Y.M. (1995) Introduction to Fuzzy Theory and Neural Networks and Their Application. Tsinghua University Press, Beijing.

[5] Jie, H.B., Kang, J.T. and Li, P. (2011) Fuzzy PID Controller Based on Variable Universe for Excitation System. Electric Power Automation Equipment, 6, 101-104.

[6] Jin, X., Deng, Z.L. and Zhang, H.M. (2007) Simulation of Synchronous Excitation Controller Based on Fuzzy-PID Control. Power System Protection and Control, 19, 13-15, 21.

[7] Yang, X.Y. (2009) Design of Parameter Self-Tuning Fuzzy Controller Based on Matlab. Automation Panorama, 12, 76-79.

[8] Oh, S.-K. and Pedrycz, W. (2002) The Design of Hybrid Fuzzy Controllers Based on Genetic Algorithms and Estimation Techniques. Emerald Group Publishing Limited, Bingley.

[9] Markovska, N., Duic, N., Iliev, O.L., Sazdov, P., et al. (2014) A Fuzzy Logic-Based Controller for Integrated Control of Protected Cultivation. Emerald Group Publishing Limited, Bingley. 